\title{
INVESTIGATION OF QUALITY TARGET PROCESS PARAMETERS (QTPP) AND CRITICAL MATERIAL ATTRIBUTES (CMA) OF NANOCELLULOSE AS A POTENTIAL EXCIPIENT
}

\author{
ROSHNI VORA ${ }^{1,2}$, YAMINI SHAH ${ }^{2}$
}

${ }^{1}$ Gujarat Technological University, Chandkheda, Ahmedabad, Gujarat, India, ${ }^{2}$ Department of Pharmaceutics and Pharmaceutical Technology, L. M. College of Pharmacy, Ahmedabad, Gujarat, India Email: mehtaroshni1989@gmail.com

Received: 18 Apr 2019, Revised and Accepted: 01 Jun 2019

\begin{abstract}
Objective: The current work highlights the use of the Quality by Design (QbD) for optimization of Nanocellulose (NC) production from corn husk by two techniques, namely, Acid hydrolysis $(\mathrm{AH})$ and High pressure homogenization (HPH).

Methods: Characterization of NC involved Fourier transform infrared spectroscopy (FTIR), thermo gravimetric analysis (TGA), X-ray diffraction (XRD), transmission electron microscopy (TEM). For the risk assessment, QbD Software was used. According to this results $3^{2}$ factorial design was applied in which two independent variables (acid concentration and time for AH whereas pressure and no of passes for HPH) and two dependent variables (particle size and yield) were selected.

Results: FTIR showed similarity in the peaks which indicates there is no change in parent molecular structure of cellulose. TGA confirmed that the NC extracted by both the methods showed improved thermal property at onset temperature of $290{ }^{\circ} \mathrm{C}$ as compared to Avicel PH101, $270{ }^{\circ} \mathrm{C}$. XRD results showed that the crystallinity index of the extracted nano cellulose from both the method was $83.15 \%$ which indicates transition and reorientation of corn husk into compact crystalline cellulosic structure after removal of non-cellulosic materials. TEM images indicated that the fibers were well dispersed and the treatment had reduced the size of fibers with average dimensions of 100 to $1000 \mathrm{~nm}$ in length. Product assay revealed that as the acid concentration and time is increased, narrow particle size is observed whereas lower number of passes and pressure resulted in a broader particle size. Studies on the variables and the experiment of NC preparation contributed a maximum yield of $77 \%$ in case of AH and $83 \%$ in case of $\mathrm{HPH}$.
\end{abstract}

Conclusion: Evident from the results, NC prepared by QbD approach had better flow property and compatibility. Hence it is suitable for usage as an excipient in product design for variety of tailor made customized oral dosage forms in pharmaceutical industry.

Keywords: Corn husk, Nanocellulose, Acid hydrolysis, High pressure homogenizer, Quality by design, Factorial design

(C) 2019 The Authors. Published by Innovare Academic Sciences Pvt Ltd. This is an open access article under the CC BY license (http://creativecommons.org/licenses/by/4.0/) DOI: http://dx.doi.org/10.22159/ijap.2019v11i4.33656

\section{INTRODUCTION}

Cellulose is highly known for its excellent properties such as renewability, biodegradability, biocompatibility, high specific surface areas, low density, low thermal expansion, good optical property, excellent mechanical property and high chemical reactivity [1-5], as a result of which it has drawn attention from various researchers across the globe [6]. Cellulose is composed of linear homopolysaccharide composed of repeating $\beta$-Dglucopyranosyl units joined by $1-4$ glycosidic linkages in a variety of arrangements [7] having amorphous and crystalline regions, which when subjected to proper mechanical, chemical and enzymatic treatments, the individualized nanofibers, can be extracted by breaking down the amorphous regions [8].

The appropriate particle size and powder rheological properties make the material suitable for direct tablet compression [9-11]. Direct compression improves the economic aspects by reducing the technological process steps. In industrial production, it is important to carry out a risk assessment before applying new technologies. Errors in critical parameter selection have the potential to adversely affect the quality of product which in turn can result in rejection, leading to financial losses hence the application of "Quality by Design" (QbD). QbD concept is a fairly new approach in the development phase of pharmaceutical products [12-16] as stated in International Conference on Harmonization (ICH) Q8 and Q9 guidelines of technical requirements for registration of pharmaceuticals for human use. Basically it is a systematic process for the assessment, control, communication, and review of risks to the quality of the APIs through the product lifecycle. The concept of QbD provides scientific-basis for product development, which involves identification of the quality target product profile (QTPP) consisting of critical quality attributes (CQAs), critical material attributes (CMAs) and critical process parameters (CPPs) using risk assessment and optimization of data using design of experiments
(DoE) [17-19]. Based on the ICH Q8 (R2) guideline, the QTPP means the quality characteristics of a drug product that optimally will be achieved to ensure the desired quality-as promised on the labeltaking into account safety and efficacy. A CQA is a physical, chemical, biological, or microbiological property that should meet the predefined requirements to ensure the desired product quality. CQAs are usually associated with the active ingredient, excipients, intermediates and drug product. CQAs of solid dosage forms affect product purity, strength, drug release and stability. A CMA is a physical, chemical, biological or microbiological property or characteristic of an input material that should be within an appropriate limit, range, or distribution to ensure the desired quality of output. The variability of a process parameter always has an impact on the CQAs. We call the process parameters "CPPs" if they have a direct impact on CQAs; therefore, these should be monitored and controlled in order to produce the desired quality. Ishikawa diagram is one of the quality management tools available in Minitab Software (Version 1.3.6., 2014 QbD Works LLC, Fremont, CA, USA) and also referred under $\mathrm{ICH}$ guideline Q9. Risk assessment aims at identifying which material attributes and process parameters potentially influence the product CQAs. Furthermore, it helps in identifying significant factors that will be subjected to the DoE study to establish product and process design space (DS) [20-23]. To ensure dependent variables can be measured, the critical parameters of both the techniques involved in production of $\mathrm{NC}$ based on the results of risk assessment were determined post which $3^{\wedge} 2$ factorial design was applied for the current study [24-26].

\section{MATERIALS AND METHODS}

\section{Materials}

Corn husk, an agricultural waste was collected by the local farmers in Gujarat, India. Sodium hydroxide [NaOH] [reagent grade, 98\%], 
hydrochloric acid [HCl] [ACS reagent, 37\%], and Calcium hypochlorite [technical grade] were supplied by Sigma-Aldrich. Aqueous solution of sodium hypochlorite was prepared by dissolution of calcium hypochlorite and sodium hydroxide in water, with subsequent filtration of the calcium hydroxide precipitates formed. As the mean particle size and yield were key parameters for our work, all of these values for the initial material and the target product are shown in table 1 . The values of the parameters of the target product were described based on the literature and self-made pre-experiments.

\section{Methods for production of NC}

NC was prepared using acid hydrolysis and high pressure homogenization as per fig. 1 .

Table 1: Comparison of the initial material and the target product

\begin{tabular}{lll}
\hline & Initial material & \multicolumn{1}{c}{ Target product } \\
\hline Mean particle size $(\mu \mathrm{m}-\mathrm{nm})$ & $55 \mu \mathrm{m}$ & $100-1000 \mathrm{~nm}$ \\
Yield $(\%)$ & - & $75-85$ \\
\hline
\end{tabular}

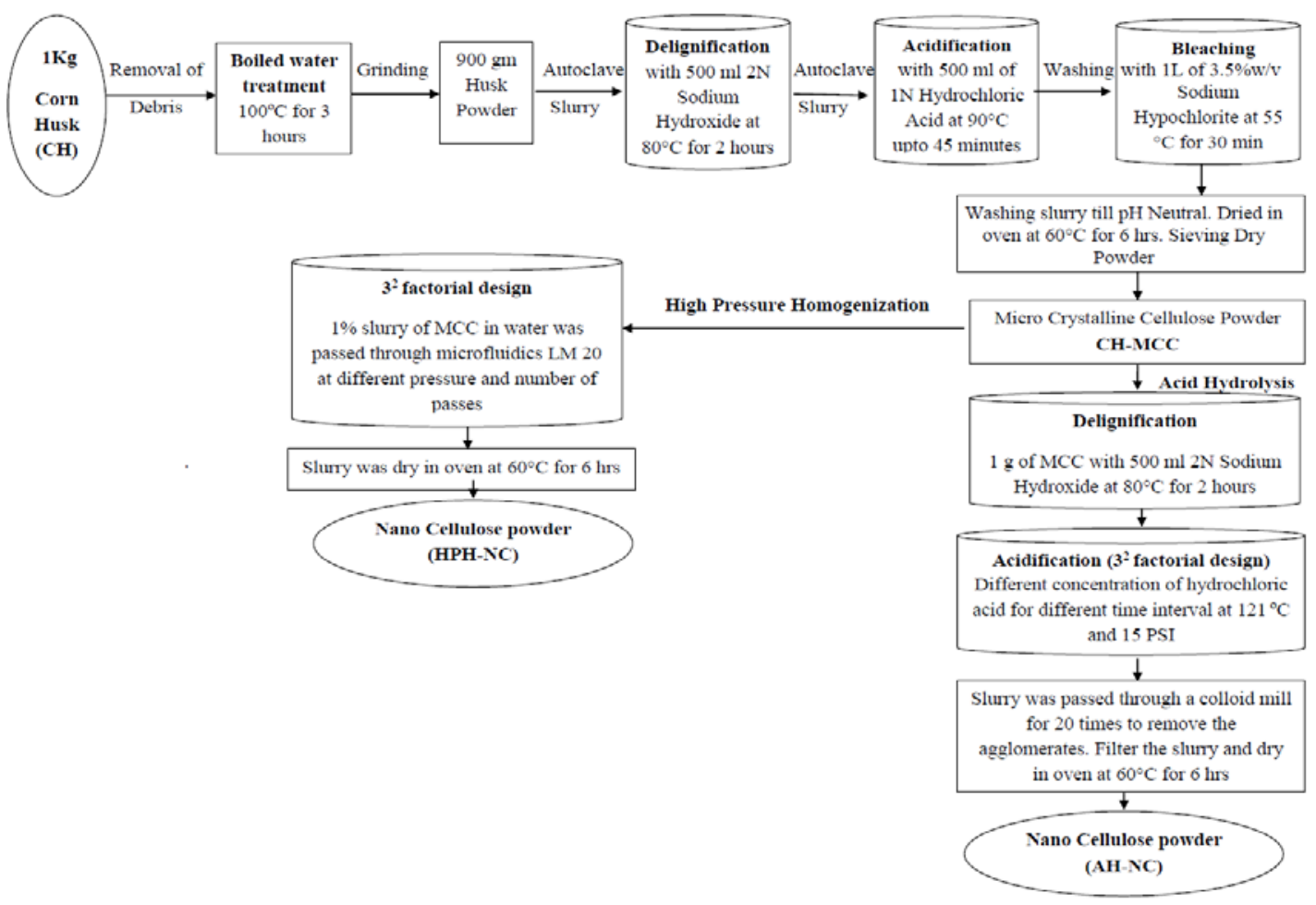

Fig. 1: Process steps for the production of the NC

\section{Investigation of the morphology}

\section{Fourier transform infrared spectroscopy (FTIR)}

The chemical composition were analyzed in the range of $400 \mathrm{~cm} 1$ to $4000 \mathrm{~cm}+1$ by Fourier transform infrared spectroscopy (FTIR) using a using $\mathrm{KBr}$ discs on a Perkin-Elmer FT-IR spectrometer [27].

\section{X-ray diffraction (XRD)}

The crystallinity of the cellulose samples were examined in an X-ray diffractometer (Philips Xpert Mpd) with a monochromatic $\mathrm{Cu} \mathrm{Ka}$ radiation source in the step-scan mode with a $2 \theta$ angle ranging from 5 to $80^{\circ}$ at a scan rate of $1^{\circ} / \mathrm{min}$ with a resolution of $0.05^{\circ}$. The operating voltage and current were $30 \mathrm{kV}$ and $200 \mathrm{~mA}$, respectively. The crystallinity index was calculated with following equation. [28].

$$
\mathrm{CI}=(\mathrm{I} 002-\mathrm{Iam}) / \mathrm{I} 002 * 100
$$

Where $\mathrm{CI}$ is the crystallinity index, $\mathrm{I} 002$ is the maximum intensity of the diffraction from the 002 plane, and Iam is the intensity of scattered by the amorphous part of the sample.

\section{Thermo gravimetric analysis (TGA)}

The thermal properties of the cellulose samples were investigated by TGA and DSC on a simultaneous thermal analyzer [Mettler-
Toledo AM, Greifensee, Switzerland]. Samples weighing between 6 and $10 \mathrm{mg}$ were used. Each sample was heated from room temperature to $500{ }^{\circ} \mathrm{C}$ at a rate of $5{ }^{\circ} \mathrm{C} / \mathrm{min}$ under nitrogen [29].

\section{Transmission electron microscopy (TEM)}

The homogenized NC suspension was dropped onto a copper grid using a pipette. The excessive water was drained with a filter paper. Then the copper grid was background stained with 2 wt $\%$ uranyl acetate. The redundant liquid was drawn away using a filter paper. The grid was air dried at room temperature and then tested with Philips Tecnai T20 electron microscope, operating at $200 \mathrm{~K} \mathrm{KeV}$. The dimensions of the imaged $\mathrm{NC}$ were determined from imaging at lower magnification from $19,000 x$ to $50,000 x$ [29].

\section{Particle size}

Particle size of the cellulose samples were measured using a Malvern Nano-ZS particle size. Before the test, the suspension were homogenized for $10 \mathrm{~min}$ at $13000 \mathrm{rpm}$ using a high-speed homogenizer, and then kept in the ultrasonic bath [29].

\section{Carr's index (CI)}

Bulk density $(\rho b)$ and the tapped density ( $\rho t)$ of the sample were determined with a bulk/tap density test apparatus (Elecrolab, EDT1020). Carr's index [30] was calculated as one hundred times the ratio 
of the difference between the tapped density and bulk density to the tapped density was calculated by utilize the following equation

$$
C I=[(\rho t-\rho b) / \rho t] \times 100
$$

\section{Hausner's ratio (HR)}

Hausner's ratio [31] is the ratio of bulked density to the tapped density. Hausner's ratio was calculated according to the following equation

$$
H R=\rho b / \rho t
$$

\section{Angle of repose}

It is defined as the angle between the free surfaces of a pile of powder to a horizontal plane. In the present study, the angle of repose was determined using a fixed cone method [32]. The sample was carefully poured through the funnel until the apex of the cone thus formed just touched the tip of the funnel. The mean radius $(\mathrm{r})$ and height (h) of the heap were measured and the angle of repose (AR) was calculated from the following equation.

$$
\tan \theta=h / r
$$

\section{RESULTS AND DISCUSSION}

\section{Risk assessment: ishikawa diagram}

As shown in fig. 2 an Ishikawa (fishbone) diagram was constructed to identify the effects of the key material attributes and process parameters on the development of the production steps of $\mathrm{NC}$ using AH and HPH method.

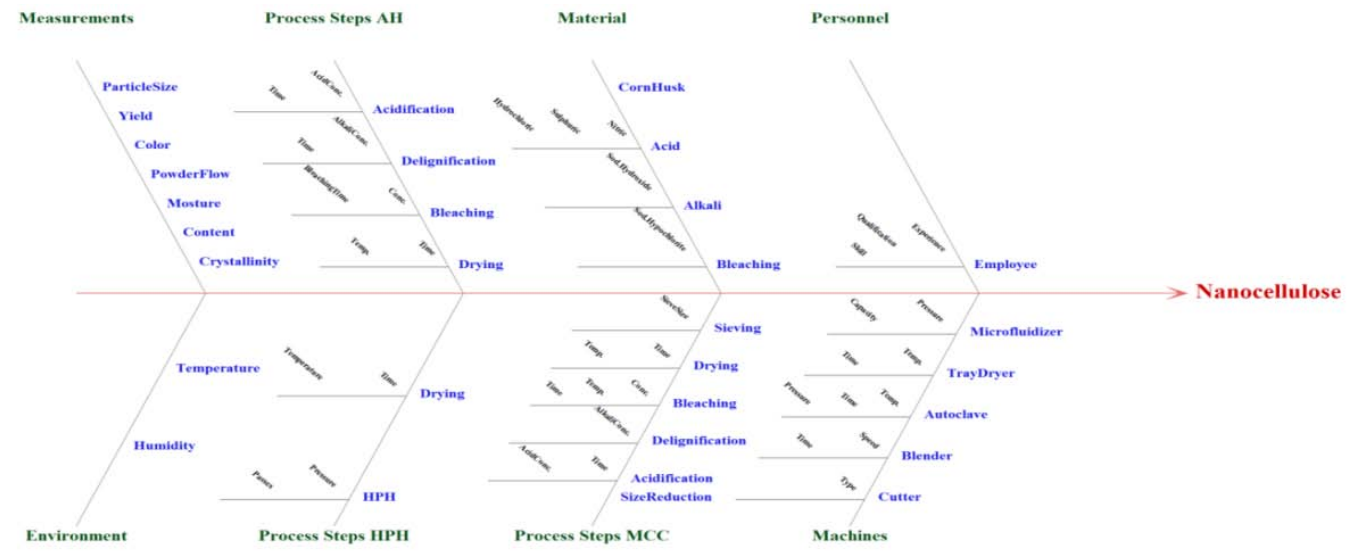

Fig. 2: Ishikawa diagram for the identification of production parameters of NC

\section{Definition of the QTPPs and Identification of the CQAs}

Based on the literature and pilot experiments, QTTPs and CQAs were determined and are shown in tables 2 and 3, together with their justification. After the identification of the QTPPs and the CQAs, the following step was to determine the critical material attributes and process parameters (CMAs and CPPs) by risk estimation matrix (REM) which represents the potential risks associated with each material attribute and process parameter that has a profound effect on CQAs. By assigning low (L), medium (M), and high $(\mathrm{H})$ values for each parameter, the REM of interdependence rating between the CQAs and QTTPs was

\begin{tabular}{|c|c|c|}
\hline QTPP & Target & Justification \\
\hline $\begin{array}{l}\text { Direct compressible } \\
\text { material }\end{array}$ & $\begin{array}{l}\text { Direct } \\
\text { compressible }\end{array}$ & $\begin{array}{l}\text { Cellulose is most commonly used excipient in the tablet. Direct compression tablet making is a simple } \\
\text { and fast method and is usable for active ingredients that are moisture sensitive. }\end{array}$ \\
\hline $\begin{array}{l}\text { Physical attributes: } \\
\text { Color, Odor and } \\
\text { Appearance }\end{array}$ & $\begin{array}{l}\text { Acceptable to } \\
\text { consumer }\end{array}$ & $\begin{array}{l}\text { Color, odor and appearance were not considered as critical, as these are not directly linked to patient } \\
\text { efficacy and safety }\end{array}$ \\
\hline $\begin{array}{l}\text { Powder rheology } \\
\text { attributes }\end{array}$ & Good flow & Better flowing properties simplify industrial operability of the powder. \\
\hline Particle Size & Smaller particles & $\begin{array}{l}\text { Smaller particles posses better powder rheology parameters, which simplifies direct tablet making. } \\
\text { Direct compression is an easy tableting method that avoids the long process of granulation. }\end{array}$ \\
\hline Yield & $100 \%$ & Yield should be $100 \%$ as production point of view so it was considered as critical \\
\hline
\end{tabular}
established. The interdependences of the factors are shown in table 4.

\section{Table 2: QTPPs of the NC produced by the AH and HPH}

\begin{tabular}{|c|c|c|c|}
\hline $\begin{array}{l}\text { Quality attributes of } \\
\text { the product }\end{array}$ & Target & $\begin{array}{l}\text { Is it } \\
\text { CQAs }\end{array}$ & Justification \\
\hline $\begin{array}{l}\text { Physical attributes: } \\
\text { Color, Odor and } \\
\text { Appearance }\end{array}$ & $\begin{array}{l}\text { Acceptable to } \\
\text { consumer }\end{array}$ & No & $\begin{array}{l}\text { Color, odor and appearance were not considered as critical, as these are not directly } \\
\text { linked to patient efficacy and safety }\end{array}$ \\
\hline Particle size & $<100$ to $500 \mathrm{~nm}$ & Yes & $\begin{array}{l}\text { This was considered highly critical as it would show direct effect on ultimate goal of } \\
\text { achieving satisfactory homogeneity, flow, and disintegration of dosage form }\end{array}$ \\
\hline Yield & $100 \%$ & Yes & Yield should be $100 \%$ from production point of view so it was considered as critical \\
\hline Angle of Repose & $25-40$ & Yes & Angle of repose, carr's index, hausner's ratio show the powder rheology attributes of the \\
\hline Carr's Index & $1-25$ & Yes & powder. Particles with "good" flow properties are suitable for direct compression \\
\hline Hausner ratio & $1.00-1.34$ & Yes & \\
\hline
\end{tabular}

Table 3: CQAs of the NC 
Table 4: QTPPs, CMAs, CPPs, CQAs and their impact on the production of NC

\begin{tabular}{|c|c|c|c|c|c|}
\hline QTPPs & Impact & CQAs & \multicolumn{2}{|l|}{ CMAs and CPPs } & Occurrence \\
\hline Particle Size & High & $\begin{array}{l}\text { Physical attributes } \\
\text { (Colour, odour, appearance) }\end{array}$ & \multicolumn{2}{|l|}{ Reaction Time (CPP) } & High \\
\hline Yield & High & Particle Size & \multicolumn{2}{|c|}{ Acid/Alkali Concentration (CPP) } & High \\
\hline Powder & Medium & Angle of Repose & \multicolumn{2}{|c|}{ No of Passes and Pressure (CPP) } & High \\
\hline & Low & $\begin{array}{l}\text { Carr's Index } \\
\text { Hausner ratio }\end{array}$ & \multicolumn{2}{|l|}{ Solvent Type (CMA) } & Medium \\
\hline CQAs/QTPPs & & $\begin{array}{l}\text { Direct compressible } \\
\text { material }\end{array}$ & \multicolumn{2}{|l|}{ Yield } & Powder rheology \\
\hline Physical attributes & & $\mathrm{L}$ & \multicolumn{2}{|l|}{$\mathrm{L}$} & $\mathrm{L}$ \\
\hline Particle Size & & $\mathrm{H}$ & \multicolumn{2}{|l|}{ M } & $\mathrm{H}$ \\
\hline Yield & & M & \multicolumn{2}{|l|}{$\mathrm{H}$} & $\mathrm{H}$ \\
\hline Angle of Repose & & $\mathrm{H}$ & \multicolumn{2}{|l|}{ M } & $\mathrm{H}$ \\
\hline Carr's Index & & $\mathrm{H}$ & \multicolumn{2}{|l|}{ M } & $\mathrm{H}$ \\
\hline Hausner ratio & & $\mathrm{H}$ & \multicolumn{2}{|l|}{ M } & $\mathrm{H}$ \\
\hline \multicolumn{2}{|l|}{ CQA/CPP/CMA } & Reaction Time (CPP) & $\begin{array}{l}\text { Acid/Alkali Conc. } \\
\text { (CPP) }\end{array}$ & $\begin{array}{l}\text { No of Passes and Pressure } \\
\text { (CPP) }\end{array}$ & $\begin{array}{l}\text { Solvent Type } \\
\text { (CMA) }\end{array}$ \\
\hline \multicolumn{2}{|l|}{ Physical attributes } & $\mathrm{L}$ & $\mathrm{L}$ & $\mathrm{L}$ & $\mathrm{L}$ \\
\hline \multicolumn{2}{|l|}{ Particle Size } & $\mathrm{H}$ & $\mathrm{H}$ & $\mathrm{H}$ & $\mathrm{H}$ \\
\hline \multicolumn{2}{|l|}{ Yield } & M & M & M & M \\
\hline \multicolumn{2}{|l|}{ Angle of Repose } & $\mathrm{H}$ & $\mathrm{H}$ & $\mathrm{H}$ & $\mathrm{H}$ \\
\hline \multicolumn{2}{|l|}{ Carr's Index } & $\mathrm{H}$ & $\mathrm{H}$ & $\mathrm{H}$ & $\mathrm{H}$ \\
\hline \multicolumn{2}{|l|}{ Hausner ratio } & $\mathrm{H}$ & $\mathrm{H}$ & $\mathrm{H}$ & $\mathrm{H}$ \\
\hline
\end{tabular}

QTPPs, CMAs, CPPs, and CQAs and their interdependence rating with the risk estimation matrix $(\mathrm{REM}): \mathrm{L}=$ low-risk parameter; $\mathrm{M}=$ medium-risk parameter; $\mathrm{H}=$ high-risk parameter.

\section{Optimization of formulation using $\mathbf{3}^{2}$ full factorial design}

$3^{\wedge} 2$ level factorial design was planned considering the critical parameters of the $\mathrm{NC}$, which were determined by small-volume preexperiments and evaluated by Mini $\mathrm{Tab}^{\mathrm{TM}}$ Software. Reaction time and acid concentration for $\mathrm{AH}$ and pressure and No of Passes for HPH were selected as independent variables. Dependent variables considered in the factorial design were particle size and yield based on the severity scores of CQAs. The levels of the factors are shown in table 5 .

Table 5: Independent and dependent variables with their levels

\begin{tabular}{llll}
\hline Acid hydrolysis (AH) & & & \\
\hline Independent variables & Levels & Medium (0) & High (1) \\
\cline { 2 - 4 } & Low (-1) & 45 & 60 \\
\hline X1 Time (Minutes) & 30 & 1 & 1.5 \\
X2 Acid Concentration (N) & 0.5 & & \\
High pressure homogenizer (HPH) & & Medium (0) & High (1) \\
\hline Independent Variables & Levels & 26000 \\
\hline X1 Pressure (PSI) & 22000 & 24000 & 15 \\
X2 No of Passes & 5 & 10 & \\
\hline
\end{tabular}

Reproducibility of the process was checked, relative standard deviation was calculated. This showed that the methods were reproducible. The polynomial functions of the correlations are described. The lack of fit analysis (data not shown) showed that a quadratic model was appropriate for the description of all responses.

The quadratic equations for the responses are shown in table 6 .

Table 6: Quadratic equations for the responses

\begin{tabular}{ll}
\hline \multicolumn{2}{l}{ Acid hydrolysis } \\
\hline $\mathrm{Y} 1$ & $844.46-126.51 \mathrm{X}_{1}-373.96 \mathrm{X}_{2}+8.3 \mathrm{X}_{12}+18.05 \mathrm{X}_{1}{ }^{2}+75.2 \mathrm{X}_{2}{ }^{2}$ \\
$\mathrm{Y} 2$ & $81.44-1.66 \mathrm{X}_{1}-2.5 \mathrm{X}_{2}-0.5 \mathrm{X}_{12}-1.66 \mathrm{X}_{1}{ }^{2}-1.16 \mathrm{X}_{2}{ }^{2}$ \\
$\mathrm{H}$ & \\
$\mathrm{Y} 1$ & $892.45-180.47 \mathrm{X}_{1}-408.11 \mathrm{X}_{2}-1.82 \mathrm{X}_{12}+68.61 \mathrm{X}_{1}{ }^{2}-11.98 \mathrm{X}_{2}{ }^{2}$ \\
$\mathrm{Y} 2$ & $77.44-2.66 \mathrm{X}_{1}-2 \mathrm{X}_{2}-1.25 \mathrm{X}_{12}+2.33 \mathrm{X}_{1}{ }^{2}+3.33 \mathrm{X}_{2}{ }^{2}$ \\
\hline
\end{tabular}

For obtaining design space surface plots were generated as shown in fig. 3. In AH, concentration of acid and time of treatment (fig. 3a) whereas in $\mathrm{HPH}$, number of passes and pressure correlated directly with the particle size range of NC (fig. 3b). As the acid concentration and time is increased, narrow particle size distribution is observed. Lower number of passes and pressure resulted in a broader particle size distribution profile. Acid concentration and time resulted in narrower yield (fig. 3c). Decrease in number of passes and pressure resulted in higher yield (fig. 3d).

\section{FTIR analysis}

Spectrum of AH-NC, HPH-NC and Avicel PH101 of FT-IR is shown in fig. 4. The FTIR spectra revealed that all finger print peaks for isolated $\mathrm{NC}$ are concordant with standard peaks reported in the literature for other celluloses. NC prepared using AH and HPH demonstrated comparable IR spectra with marketed cellulose Avicel PH101. 

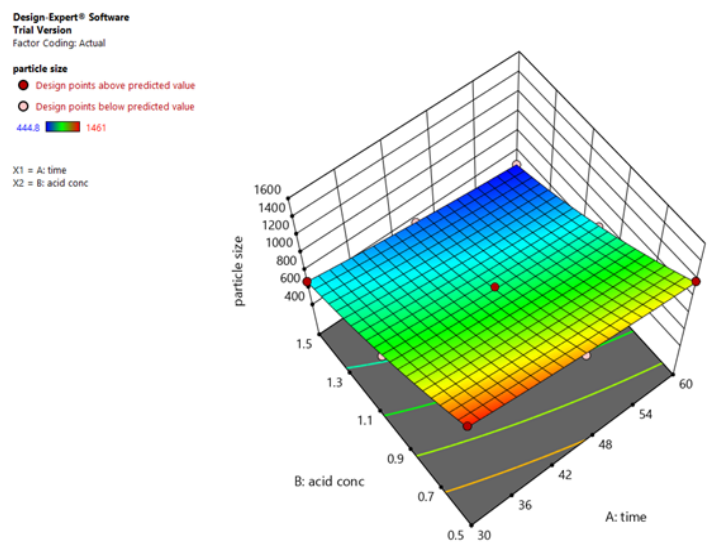

(a)
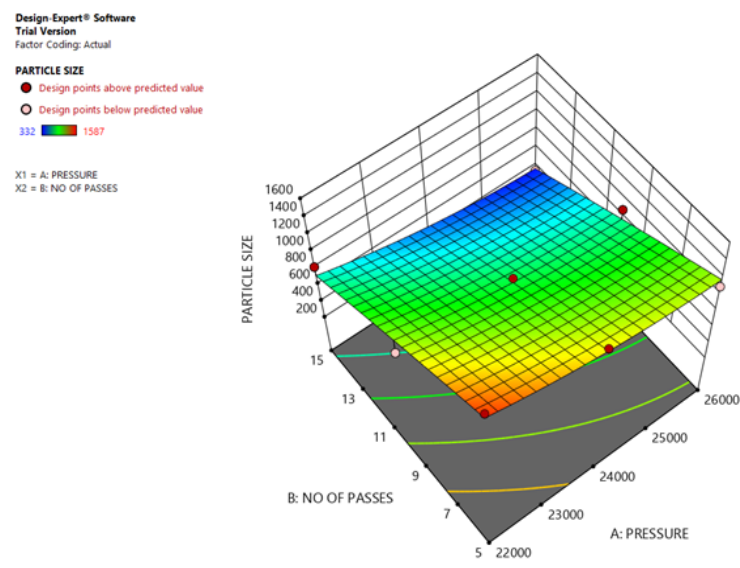

(c)
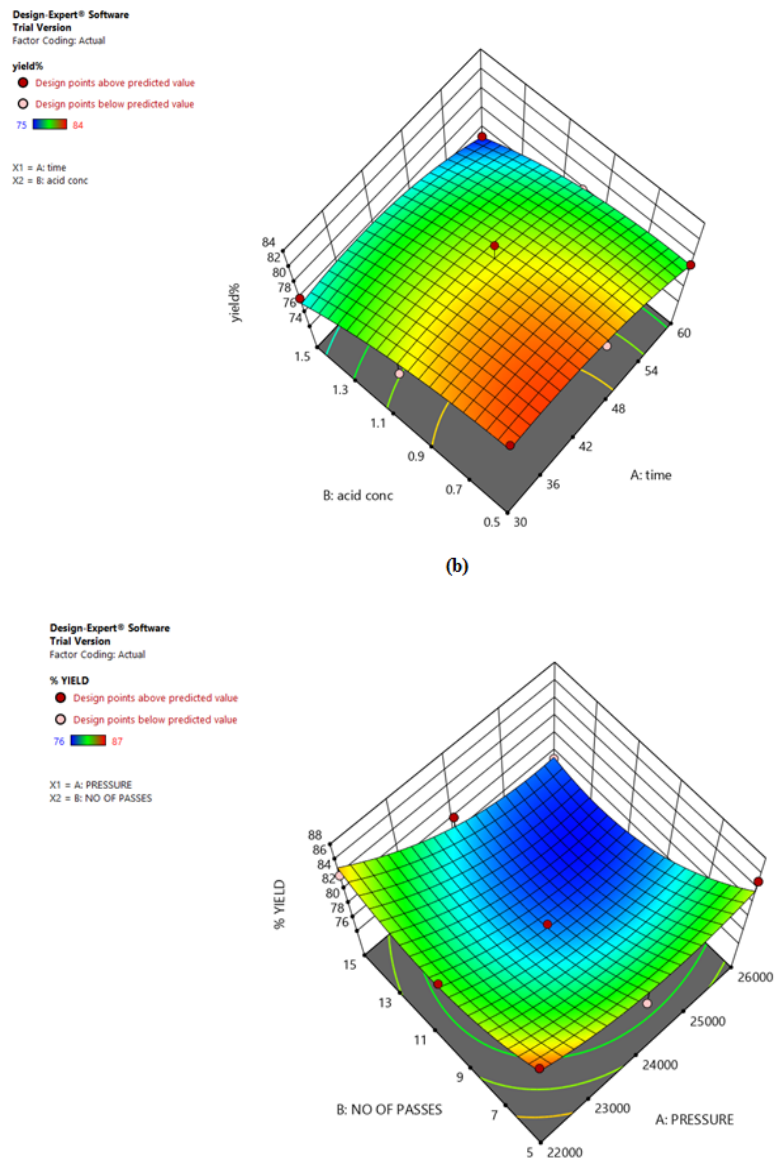

(d)

Fig. 3: Effect of variables on yield and particle size a) acid concentration and reaction time on mean particle size b) acid concentration and reaction time on yield c) number of passes and pressure on mean particle size d) number of passes and pressure on yield

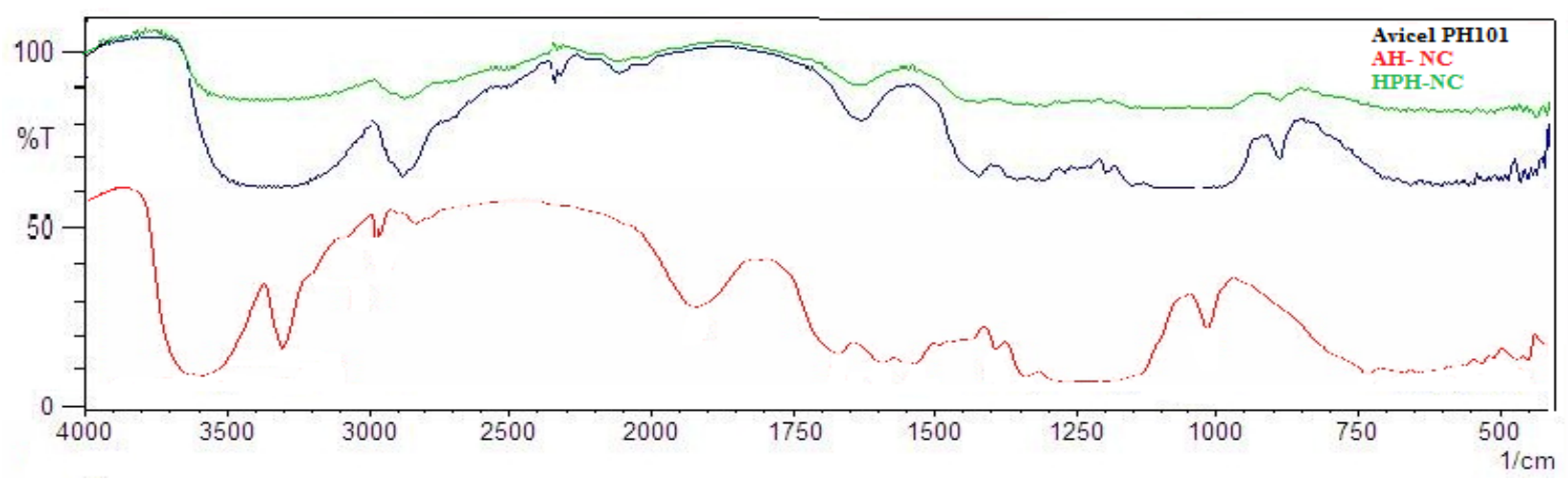

Fig. 4: FTIR spectra of the cellulose samples AH-NC, HPH-NC, Avicel PH101

Absorption bands around 3400, 1430, 1370 and $890 \mathrm{~cm}-1$ are characteristically attributed to cellulose [33]. The broad absorption at 3400-3600 cm-1 is assigned to the stretching vibration of-OH groups [34], and the absorption at $2920 \mathrm{~cm}-1$ is ascribed to the $\mathrm{C}-\mathrm{H}$ stretching vibration [35]. The peak at $1645 \mathrm{~cm}-1$ is related to the bending mode of the water molecule resulting from a strong interaction between water and cellulose [36]. Other adsorption peaks are mainly assignable to the intermolecular hydrogen attraction at the $\mathrm{C} 6$ group at $1425 \mathrm{~cm}-1, \mathrm{C}-\mathrm{O}-\mathrm{C}$ glycosidic band stretching vibration at $1163 \mathrm{~cm}-1$ and C-H rock vibration at $896 \mathrm{~cm}$ 1. Aromatic $\mathrm{C}-\mathrm{H}$ out-of-plane bending vibration in lignin at $828 \mathrm{~cm}-1$ [37] did not appear in the spectrum exhibiting complete removal of lignin by chemical pretreatment.

\section{Thermal stability of NC}

The thermal stability of the AH-NC and HPH-NC was investigated by thermo gravimetric analysis (TGA) and differential Scanning Calorimetry (DSC). 


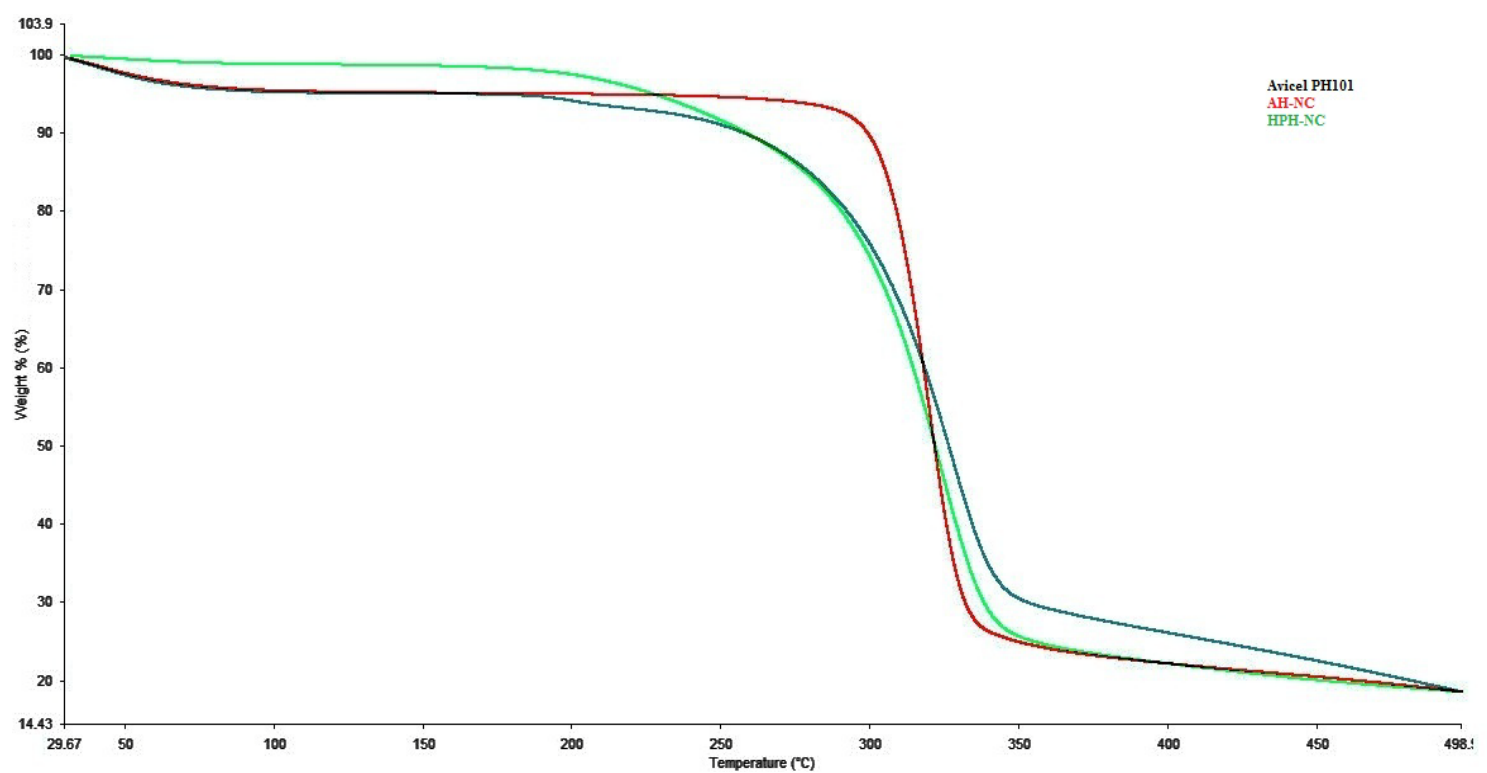

Fig. 5: TGA thermograms of AH-NC, HPH-NC, Avicel PH101

The thermo grams in fig. 5 show that Avicel PH 101, AH-NC and HPH-NC follow similar degradation patterns. As shown in table 7 , TGA profiles of Avicel PH 101, AH-NC and HPH-NC are identica with respect to $\mathrm{T} 5 \%, \mathrm{~T} 50 \%$ and $\mathrm{W}_{500}(\%)$. T5\% and $\mathrm{T} 50 \%$ are the temperature for which $5 \%$ and $50 \%$ of the mass is decomposed respectively, whereas, $W_{500}(\%)$ denotes char yield. Initial weight loss represents evaporation of loose bound free water on the surface and also due to removal of the protective waxes and lignin layers from the fiber. Lower residual char value at $500{ }^{\circ} \mathrm{C}$ for $\mathrm{AH}-$ $\mathrm{NC}$ and HPH-NC indicating lower amounts of residual solids. This could be an indicator for the absence of hemicellulose or lignin [38].

Table 7: Thermal properties for AH-NC, HPH-NC, Avicel PH101

\begin{tabular}{llll}
\hline Parameter & Avicel PH 101 & AH-NC & HPH-NC \\
\hline $\mathrm{T}_{5 \%}$ onset $\left({ }^{\circ} \mathrm{C}\right)^{\mathrm{a}}$ & 244.07 & 229.51 & 200.69 \\
$\mathrm{~T}_{50 \%}\left({ }^{\circ} \mathrm{C}\right)^{\mathrm{b}}$ & 330.75 & 318.69 & 326.58 \\
$\mathrm{~W}_{500}(\%)^{\mathrm{c}}$ & 19.113 & 15.23 & 6.10 \\
\hline
\end{tabular}

${ }^{\mathrm{a}}$ onset temperature for $5 \%$ decomposition; btemperature at $50 \%$ weight loss; ${ }^{c}$ residual char weight at $500{ }^{\circ} \mathrm{C}$

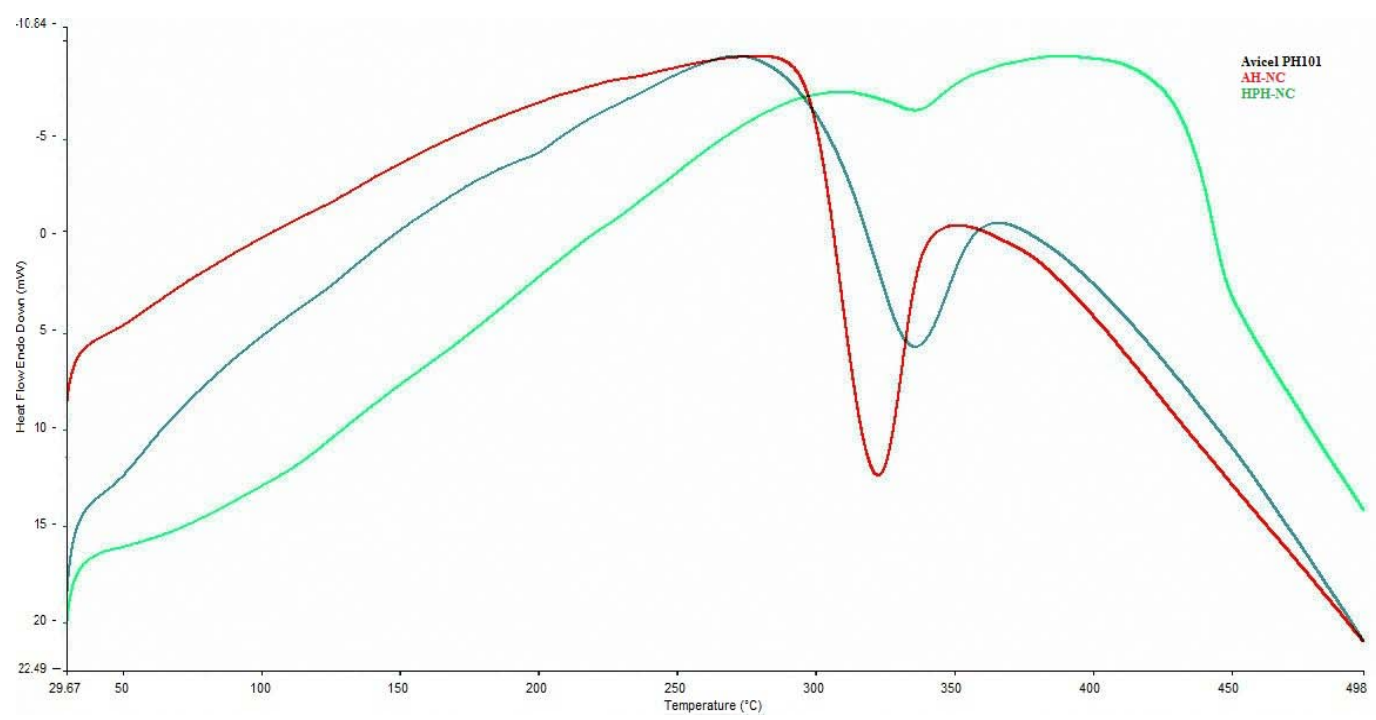

Fig. 6: DSC thermograms of the cellulose samples AH-NC, HPH-NC, Avicel PH101

\section{Differential scanning calorimetry}

As shown in fig. 6, DSC fairly corresponds with the observations made from thermo gravimetric analysis. The onset temperatures of the decomposition as well as the midpoint and inflection point temperature data for all the samples are similar and are presented in table 8. The corn husk undergoes transition and reorient in a compact crystal cellulosic structure after removal of non-cellulosic 
materials. The higher onset temperatures are associated with higher thermal stability and high degree of crystallinity. In all the thermograms cellulose showed a sharp endothermic peak at 330-
$340{ }^{\circ} \mathrm{C}$, corresponding to the fusion of its crystalline part. This behavior could be attributed to the high degree of crystallinity of the celluloses [38].

Table 8: DSC thermograms of celluloses sample AH-NC, HPH-NC, Avicel PH101

\begin{tabular}{|c|c|c|c|}
\hline Parameter & Avicel PH101 & AH-NC & HPH-NC \\
\hline Onset $\left({ }^{\circ} \mathrm{C}\right)$ & 270 & 290 & 290 \\
\hline Mid Point $\left({ }^{\circ} \mathrm{C}\right)$ & 340 & 330 & 340 \\
\hline Inflection Point $\left({ }^{\circ} \mathrm{C}\right)$ & 370 & 350 & 350 \\
\hline
\end{tabular}

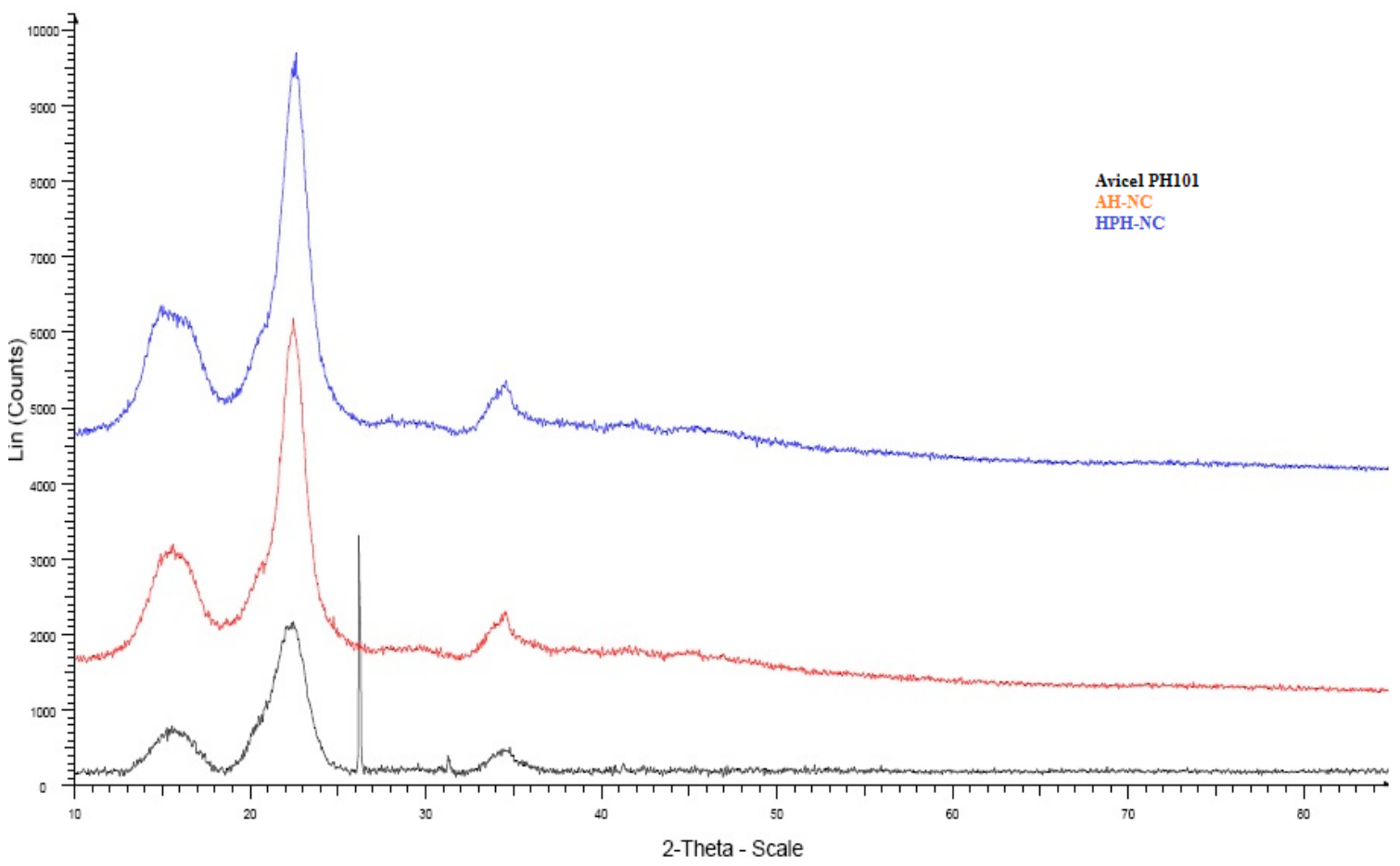

Fig. 7: X-ray diffractograms of the cellulose samples AH-NC, HPH-NC, Avicel PH101

\section{XRD analysis}

The crystallinity of Avicel PH101, AH-NC and HPH-NC is investigated using X-ray diffractometry and diffraction spectra of all cellulose samples are shown in fig 7. The diffractograms of the Avicel PH101, AH-NC and HPH-NC exhibit diffraction pattern typical of cellulose I, with diffraction peaks of the $2 \theta$ angles at $15.0^{\circ}, 14.32^{\circ}$ and $22^{\circ}$, which can be assigned to the $101,10 \hat{I}$ and 002 reflections, respectively [39]. This indicates that all the above mentioned cellulosic samples obtained from corn husk are made up of cellulose I. This might be due to short time exposure of the raw materials to low concentration of sodium hydroxide solution $(8 \% \mathrm{NaOH})$ during the cellulose isolation. It has been reported that the lattice transition from cellulose I to cellulose II sets in above $10 \%$ of sodium hydroxide, but it is not completed below $15 \%$ of sodium hydroxide [40]. Crystallinity index gives a quantitative measure of the crystallinity in powders and can relate to the strength and stiffness of fibres [41]. Hence, in our cellulose sample crystallinity indices (86.55\% for Avicel PH101, 83.15\% for AH-NC and $83.15 \%$ for HPHNC) are similar to those reported in other studies for MCC [42, 43]. High crystallinity indicates an ordered compact molecular structure, which translates to dense particles, whereas lower crystallinity implies a more disordered structure, resulting in a more amorphous powder.
TEM

The TEM images of AH-NC and HPH-NC are shown in fig. 8. AH-NC and HPH-NC are shown as niddle shaped particles. NC showed a broad polydispersity of $100-500 \mathrm{~nm}$ in length. $\mathrm{NC}$ is comparable in length to the nanocrystallites isolated from rice husk [44] and barley [45]. It can be concluded that the extraction methods affect the morphology and size distribution of NC. HPH is a harsh process affecting most of the disordered regions of the cellulose, whereas the acid hydrolysis alone is effective in breaking strong hydrogen bonds of native fibers dissolving most of the amorphous regions thereby resulting in an organized picture in case of $\mathrm{AH}-\mathrm{NC}$ [46].

\section{Updated risk assessment of optimized batch}

During process development, CMAs having high risks were addressed. After detailed experimentation, initial manufacturing process was updated. Table 9 shows reduction in risks for the production of nanocellulose as a result of the process development work. Obtained values of particle size and yield were in good agreement with each other. Hence, it can be concluded that the model has good predictive ability within the design space as shown in fig. 9. The test batch with a coded value of $X 1$ and $X 2$ showed desirable nano size particles as optimal batches. 


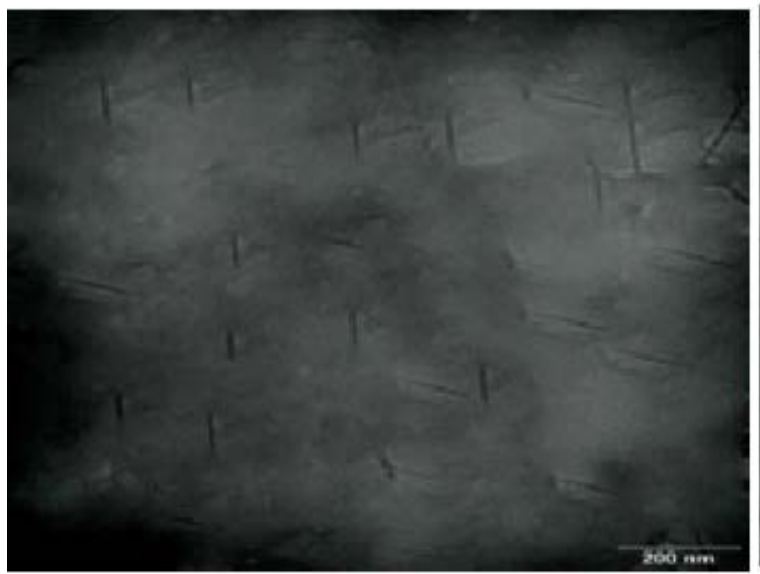

(a)

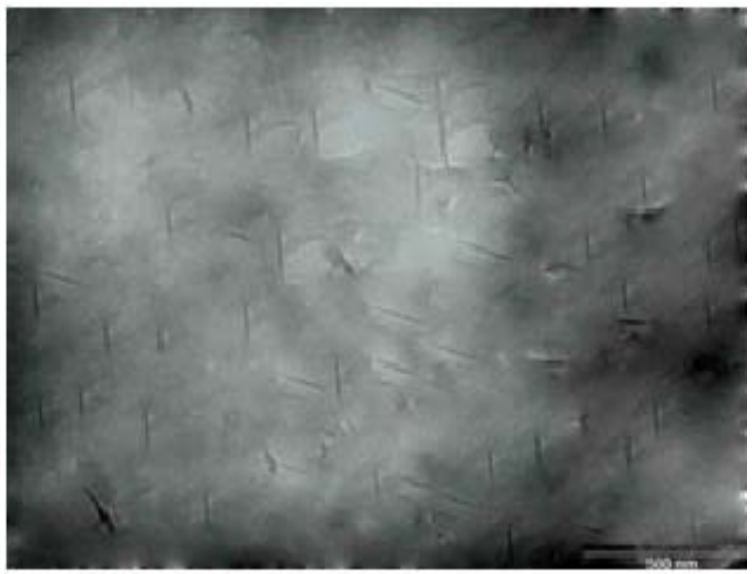

(b)

Fig. 8: TEM image of (a) AH-NC and (b) HPH-NC

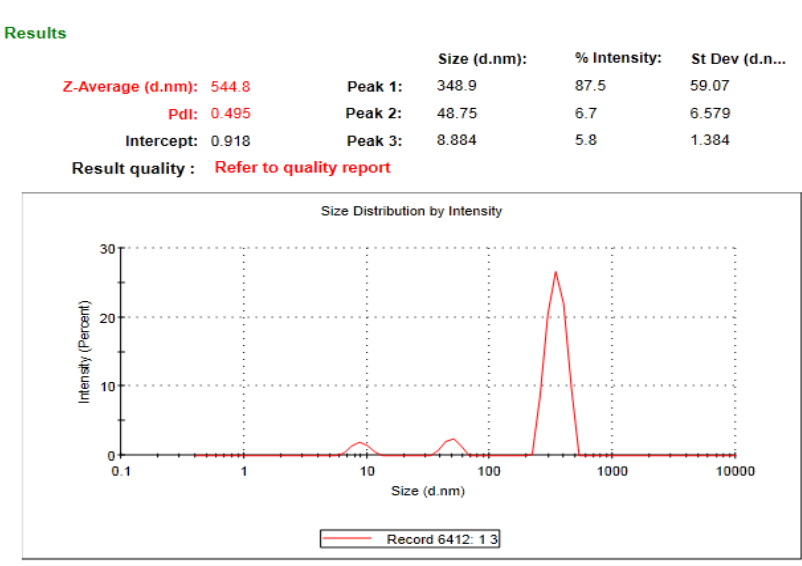

(a)

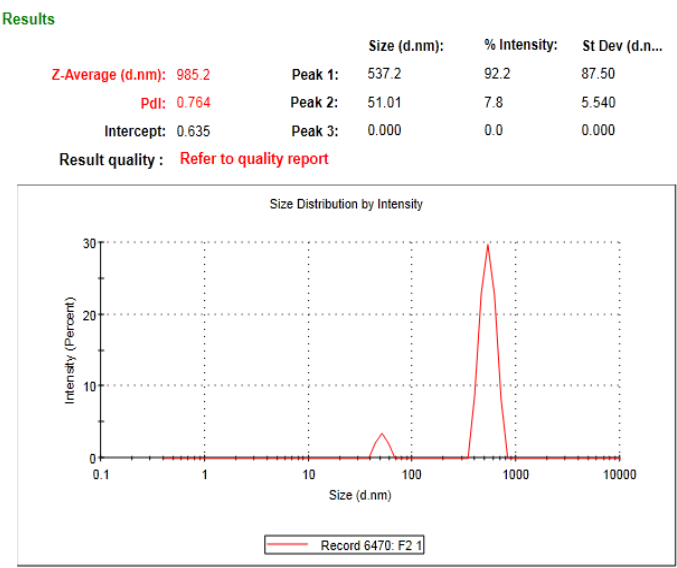

(b)

Fig. 9: Optimized batch particle size a) AH-NC b) HPH-NC

Table 9: Updated risk assessment to identify variables affecting product quality

\begin{tabular}{llll}
\hline & & Initial material & AH \\
\hline Y1 & Mean particle size $(\mu \mathrm{m}$ to $\mathrm{nm})$ & 55 & 544.8 \\
Y2 & Yield (\%) & & 985.2 \\
\hline & Applied parameters for AH & & \\
\hline $\mathrm{X} 1$ & Acid Concentration $(\mathrm{N})$ & - & $1.5(\mathrm{~L})$ \\
$\mathrm{X} 2$ & Reaction Time (min) & - & $45(\mathrm{~L})$ \\
\hline & Applied parameters for HPH & - & - \\
\hline $\mathrm{X} 1$ & Pressure & - & - \\
$\mathrm{X} 2$ & No of Passes & - & - \\
\hline
\end{tabular}

Table 10: Improvements in the powder rheological properties compression

\begin{tabular}{|c|c|c|c|c|}
\hline & Angle of repose & Carr's index & Hausner ratio & Classification USP 30 \\
\hline Initial Material & 35.4 & 22.42 & 1.26 & Passable \\
\hline AH-NC & 31.3 & 14 & 1.16 & Good \\
\hline HPH-NC & 32.24 & 18.3 & 1.22 & Fair \\
\hline
\end{tabular}

\section{Powder rheology}

Powder rheological properties of optimized batch were investigated and it was revealed that NC had far better flow properties than initial material; Carr's index and Hausner's ratio also improved compared to the initial material. This can ease the direct compression tableting reducing the amount of the additives in the final formulation. In table 10 improvements in powder rheological properties are summarized.

\section{CONCLUSION}

This study demonstrates the applicability of QbD for production of Nanocellulose by processing cellulose obtained from recycling corn husk. The chosen model helps to envision the effects of the CMAs, 
CPPs in context to CQAs. Factorial design was employed to save the time of runs for the batches, use of reactants, electricity and skilled labor. NC prepared by both methods showed similar results in instrumental analysis (FTIR, DSC, TGA, XRD and TEM) and physicochemical characterization (Carr's Index, Hausner's Ratio, Particle size and \% Yield). Between the two techniques of processing, NC produced by acid hydrolysis does not require use of modern equipment (such as high pressure homogenizer), minimizes the possibility of accidental metal contamination due to $\mathrm{HPH}$, is ecofriendly, less time consuming, cost effective, less labor intensive and has superior flow properties (which is more suitable for high-speed tablet press). Hence we would propose hydrolysis of cellulose using a dilute acid for production of NC as our method of choice for large scale production.

\section{ACKNOWLEDGMENT}

The authors express their gratitude to the L. M. College of Pharmacy, Ahmedabad, Gujarat, India for approval of financial assistance under SSIP scheme (Ref No: 154/(14)/2018) and Trident Equipments for allowing us to use their facilities and equipment to carry out this project.

\section{AUTHORS CONTRIBUTIONS}

Roshni Vora designed the experiments, carried out the processes for production of NC and composed the manuscript. Yamini Shah helped throughout the risk assessment, necessary theoretical background of the $\mathrm{QbD}$ methodology and supervised the whole process.

\section{CONFLICTS OF INTERESTS}

The authors declare no conflict of interest

\section{REFERENCES}

1. Haafiz MKM, Hassan A, Zakaria Z, Inuwa IM. Isolation and characterization of cellulose nanowhiskers from oil palm biomass microcrystalline cellulose. Carbohydrate Polym 2014;103:119-25.

2. Ng HM, Sin LT, Tee TT, Bee ST, Hui D, Low CY, et al. Extraction of cellulose nanocrystals from plant sources for application as reinforcing agent in polymers. Composites Part B: Engineering 2015;75:176-200.

3. Karim M, Mohamed NB, Julien B. Nanofibrillated cellulose surface modification: a review. Materials 2013;6:1745-66.

4. Liu DY, Yuan XW, Bhattacharyya D, Easteal AJ. Characterisation of solution cast cellulose nanofibre reinforced poly (lactic acid). eXPRESS Polym Lett 2010;4:26-31.

5. Wang Z, Carlsson DO, Tammela P, Hua K, Zhang P, Nyholm L, et al. Surface modified nanocellulose fibers yield conducting polymer-based flexible supercapacitors with enhanced capacitances. ACS Nano 2015;9:7563-71.

6. Abdul K, Davoudpour Y, Chaturbhuj KS, Hossain Md, Adnan A, Dungani R, et al. A review on nanocellulosic fibres as new material for sustainable packaging: process and applications. Renewable Sustainable Energy Rev 2016;64:823-36.

7. Robert M, Ashlie M, John N, John S, Jeff Y. Cellulose nanomaterials review: structure, properties and nanocomposites. Chem Soc Rev 2011;40:3941-94.

8. Jiang G, Zhang J, Qiao J, Jiang Y, Zarrin H, Chen Z, Hong F. Bacterial nanocellulose/Nafion composite membranes for low temperature polymer electrolyte fuel cells. J Power Sources 2014;273:697-706.

9. Goczo H, Szabo Revesz P, Farkas B, Hasznos Nezdei M, Serwanis SF, Pintye Hodi K, et al. Development of spherical crystals of acetylsalicylic acid for direct tablet-making. Chem Pharm Bull 2000;48:1877-81.

10. Kaialy W, Larhrib H, Chikwanha B, Shojaee S, Nokhodchi A. An approach to engineer paracetamol crystals by antisolvent crystallization technique in presence of various additives for direct compression. Int J Pharm 2014;464:53-64.

11. Nokhodchi A, Maghsoodi M. Preparation of spherical crystal agglomerates of naproxen containing disintegrant for direct tablet making by spherical crystallization technique. AAPS PharmSciTech 2008;9:54-9.
12. US Food and Drug Administration. Guidance for Industry: Q8 (R2) Pharmaceutical Development; Center for Drug Evaluation and Research: Silver Spring, MD, USA; 2009.

13. US Food and Drug Administration. Guidance for Industry: Q9 Quality Risk Management; US Food and Drug Administration: Silver Spring, MD, USA; 2006.

14. Kovacs A, Berko S, Csanyi E, Csoka I. Development of nanostructured lipid carriers containing salicyclic acid for dermal use based on the quality by design method. Eur J Pharm Sci 2017;99:246-57.

15. Kirrstetter R. GMP aspects in practice: the new ICH guidelines concerning quality: ICH Q8, Q9 and Q10. Pharm Ind 2005;67:213-6.

16. Vanitha C, Satyanarayana SV, Bhaskar RK. Quality by design approach to stability-indicating reverse-phase highperformance liquid chromatography method development, optimization, and validation for the estimation of simeprevir in bulk drug. Asian J Pharm Clin Res 2019;12:93-100.

17. Hales D, Vlase L, Porav SA, Bodoki A, Barbu Tudoran L, Achim M. A quality by design (QBD) study on enoxaparin sodium loaded polymeric microspheres for colon-specific delivery. Eur J Pharm Sci 2017;100:249-61.

18. Iurian S, Bogdan C, Tomuta I, Szabo Revesz P, Chvatal A, Leucuta SE, et al. Development of oral lyophilisates containing meloxicam nanocrystals using QBD approach. Eur J Pharm Sci 2017;104:356-65.

19. Adam S, Suzzi D, Radeke C, Khinast JG. An integrated quality by design (QBD) approach towards design space definition of a blending unit operation by discrete element method (DEM) simulation. Eur J Pharm Sci 2011;42:106-15.

20. Wang JL, Kan SL, Chen T, Liu JP. Application of quality by design (QBD) to formulation and processing of naproxen pellets by extrusion-spheronization. Pharm Dev Technol 2015;20:246-56.

21. Pallagi E, Ambrus R, Szabo Revesz P, Csoka I. Adaptation of the quality by design concept in early pharmaceutical development of an intranasal nanosized formulation. Int J Pharm 2015;491:384-92.

22. Karimi K, Pallagi E, Szabo Revesz P, Csoka I, Ambrus R. Development of a microparticle based dry powder inhalation formulation of ciprofloxacin hydrochloride applying the quality by design approach. Drug Des Dev Ther 2016;10:3331-43.

23. Jornil J, Jensen KG, Larsen F, Linnet K. Risk assessment of accidental nortriptyline poisoning: the importance of cytochrome p450 for nortriptyline elimination investigated using a population-based pharmacokinetic simulator. Eur J Pharm Sci 2011;44:265-72.

24. Beirao-da-Costa S, Duarte C, Moldao Martins M, Beirao-da-Costa ML. Physical characterization of rice starch spherical aggregates produced by spray-drying. J Food Eng 2011;104:36-42.

25. Paradkar AR, Pawar AP, Chordiya JK, Patil VB, Ketkar AR. Spherical crystallization of celecoxib. Drug Dev Ind Pharm 2002;28:1213-20.

26. Box GE, Hunter JS, Hunter WG. Statistics for experimenters: design, innovation, and discovery. 2nd ed. John Wiley and Sons, Inc.: Hoboken, NJ, USA; 2005.

27. Nelson ML, O'Connor RT. Relation of certain infrared bands to cellulose crystallinity and crystal lattice type II. A new infrared ratio for estimation of crystallinity in cellulose I and II. J Appl Polym Sci 1964;8:1325-41.

28. Segal L, Creely JJ, Martin AE Jr, Conrad CM. An empirical method for estimating the degree of crystallinity of native cellulose using the x-ray diffractometer. Text Res J 1959;29:786-94.

29. Xue Y, Fuyi H, Chunxia Xu, Shuai J, Liqian H, Lifang L, et al. Effects of preparation methods on the morphology and properties of nanocellulose (NC) extracted from corn husk. Industrial Crops Products 2017;109:241-7.

30. Carr RL. Evaluating flow properties of solids. Chem Eng 1965;72:163-8.

31. Amrita S, Vaibhav R, Varsha K. Formulation development and evaluation of fast dissolving tablet of ramipril. Int J Pharm Pharm Sci 2015;7:127-31.

32. Kannissery P, Jomon NB, Elambilan NB. Effect of non-volatile solvent and excipient ratio on flow and consolidation 
properties of powder blend for liquisolid compacts. Int J Pharm Pharm Sci 2015;7:150-5.

33. Haafiz MKM, Hassan A, Zakaria Z, Inuwa IM. Isolation and characterization of cellulose nanowhiskers from oil palm biomass microcrystalline cellulose. Carbohydrate Polymers 2014;103:119-25.

34. Liu Z, Li X, Xie W. Carrageenan as a dry strength additive for papermaking. Plos One 2017;12:13-26.

35. Xie W, Song Z, Liu Z, Qian X. Surface modification of PCC with guar gum using organic titanium ionic crosslinking agent and its application as papermaking filler. Carbohydrate Polymers 2016;150:114-20

36. Rosa SML, Rehman N, Miranda MIG, Nachtigall SMB, Bica CID. Chlorine-free extraction of cellulose from rice husk and whisker isolation. Carbohydrate Polymers 2012;87:1131-8.

37. Jiang F, Hsieh YL. Cellulose nanocrystal isolation from tomato peels and assembled nanofibers. Carbohydrate Polymers 2015;122:60-8.

38. Sain M, Panthapulakkal S. Bioprocess preparation of wheat straw fibres and their characterisation. Ind Crops Products 2006;23:1-8.

39. Isogai I. Allomorphs of cellulose and other polysaccharides. Gilbert RD. ed (Cincinnati) Cellulosic polymers, blends and composites. Hanser/Gardner Publications; 1994.
40. Ryshkewitch E. Compression strength of porous sintered alumina and zirconia. J Am Ceramic Soc 1953;36:65-8.

41. Wang L, Han G, Zhang Y. Comparative study of composition, structure and properties of Apocynum venetum fibers under different pretreatments. Carbohydrate Polymers 2007;69:391-7.

42. El-Sakhawy M, Hassan ML. Physical and mechanical properties of microcrystalline cellulose prepared from agricutural residues. Carbohydr Polym 2007;67:1-10.

43. Suesat J, Suwanruji P. Preparation and properties of microcrystalline cellulose from corn residues. Adv Mater Res 2011;1781-4.

44. Johar N, Ahmad I, Dufresne A. Extraction, preparation and characterization of cellulose fibres and nanocrystals from rice husk. Industrial Crops Products 2012;37:93-9.

45. Espino E, Cakir M, Domenek S, Roman Gutierrez AD, Belgacem $\mathrm{N}$, Bras J. Isolation and characterization of cellulose nanocrystals from industrial by-products of agave tequilana and barley. Industrial Crops Products 2014;62:552-9.

46. Kallel F, Bettaieb F, Khiari R, Garcia A, Bras J, Chaabouni SE. Isolation and structural characterization of cellulose nanocrystals extracted from garlic straw residues. Industrial Crops Products 2016;87:287-96. 